\title{
Role of TGF- $\beta 1$ expressed in bone marrow-derived mesenchymal stem cells in promoting bone formation in a rabbit femoral defect model
}

\author{
BING-YIN SUN ${ }^{1 *}$, BAO-XIANG ZHAO ${ }^{2 *}$, JIE-YING ZHU ${ }^{3}$, \\ ZHENG-PING SUN ${ }^{4}$, YONG-AN SHI ${ }^{5}$ and FENG HUANG ${ }^{6}$
}

${ }^{1}$ Department of Orthopedics, Shunde Hospital of Guangzhou University of Chinese Medicine, Foshan, Guangdong 528200;

${ }^{2}$ Department of Orthopedics, Linyi People's Hospital, Linyi, Shandong 276000; ${ }^{3}$ Department of Substance Dependence, The Affiliated Brain Hospital of Guangzhou Medical University (Guangzhou Huiai Hospital), Guangzhou, Guangdong 510370;

${ }^{4}$ Physical Examination Center, The Second Traditional Chinese Medicine Hospital of Guangdong Provence, Guangzhou, Guangdong 510095; ${ }^{5}$ Department of Microsurgery II, Wendeng Hospital of Traditional Chinese of Orthopedics and Traumatology of Shandong, Wendeng, Shandong 264400; ${ }^{6}$ Department of Orthopedics, The First Affiliated Hospital of Guangzhou University of Traditional Chinese Medicine, Guangzhou, Guangdong 510405, P.R. China

Received November 30, 2017; Accepted May 10, 2018

DOI: $10.3892 / \mathrm{ijmm} .2018 .3692$

\begin{abstract}
Bone defects represent a major clinical and socioeconomic problem without suitable treatment options. Previous studies have shown that transforming growth factor $\beta 1$ (TGF- $\beta 1$ ) is important in the development of various diseases. The present study aimed to investigate the therapeutic potential of rabbit bone marrow-derived mesenchymal stem cells (BMSCs) expressing TGF- $\beta 1$ in the treatment of rabbit femoral defects. First, rabbit BMSCs were identified and cultured. TGF- $\beta 1$ was then stably overexpressed in the rabbit BMSCs by lentivirus transfection, which was expressed at a high level in the femoral defects treated with TGF- $\beta 1$-overexpressing BMSCs, compared with PBS-treated controls. In addition, the TGF- $\beta 1$-overexpressing BMSCs promoted new bone formation in the rabbit femoral defect model, and increased the expression of bone-related markers at week 2 and week 6 . Therefore, the study demonstrated that BMSCs overexpressing TGF- $\beta 1$ may provide a novel therapeutic option for femoral defects.
\end{abstract}

Correspondence to: Dr Feng Huang, Department of Orthopedics, The First Affiliated Hospital of Guangzhou University of Traditional Chinese Medicine, 16 Jichang Road, Guangzhou, Guangdong 510405, P.R. China

E-mail: fhuangdoc@yeah.net

*Contributed equally

Key words: transforming growth factor- $\beta 1$, bone marrow-derived mesenchymal stem cells, rabbit femoral defect, new bone formation

\section{Introduction}

Bone defects are caused by several clinical conditions, including cancer, trauma, congenital malformation, and infection (1). The costs of medical treatment, together with the loss of income of those with these musculoskeletal diseases, in the United States of America are estimated to be $\$ 849,000,000,000$, which is $\sim 7.7 \%$ of the gross domestic product from 2002 to 2004 (1). In addition, suitable treatment options that promote bone healing are still lacking (2). Although autograft is the gold standard for the treatment of bone defects at present, this approach has two major drawbacks, namely the limited number of donor sites and the occurrence of donor site morbidity (3). Furthermore, bone regenerative ability can also be limited with increase in age (4) and by certain conditions, including arthritis and osteoporosis $(5,6)$. Therefore, those patients who require bone grafts the most may not have the autologous stem cells required for autografting. Therefore, transplantation of allogeneic stem cells is an attractive option for engineering bone tissue.

Previous studies have shown that tissues can be regenerated through tissue engineering approaches (7), and osteogenic differentiation and bone regeneration can be achieved with stem cells (8). Bone marrow-derived mesenchymal stem cells (BMSCs) were first separated in the 1970s, and are the source of several mesenchymal tissues, including fat, bone, and cartilage $(9,10)$. BMSCs are a type of multipotent mesenchymal stem cell found in bone marrow. They have a high capacity for self-renewal and the potential to differentiate into various cell types, and have long been considered a valuable source of cells for bone tissue engineering (11-14). Therefore, BMSCs have been identified as an important source of osteogenic cells for bone tissue engineering.

Transforming growth factor $\beta 1$ (TGF- $\beta 1$ ) belongs to the TGF- $\beta$ superfamily of proteins, which regulate cell growth and differentiation. The TGF- $\beta$ family includes 
activins, inhibins, Müllerian inhibitory substance, and bone morphogenetic proteins. Early studies showed that TGF- $\beta$ is important in inflammation, tissue repair, and embryonic development $(15,16)$. Subsequent studies have shown that TGF- $\beta$ is also crucial in cell growth, differentiation and immune function $(17,18)$. TGF- $\beta 1$ as a signal molecule is important in bone regeneration, and the importance of TGF- $\beta 1$ in the migration, growth and differentiation of BMSCs has been established (19). However, the effects of TGF- $\beta 1$ in combination with BMSCs on bone repair remain to be fully elucidated.

The present study showed that bone formation was highest in femoral defects treated with TGF- $\beta 1$-overexpressing BMSCs of all the experimental groups, and that the combination of BMSCs and TGF- $\beta 1$ may be a potential novel therapeutic option for femoral defects.

\section{Materials and methods}

Experimental animals and generation of the femoral defect model. A total of $42 \mathrm{New}$ Zealand white rabbits (male), weighing 2.0-2.5 kg each, aged 2-3 months, were purchased from the Experimental Animal Center at Guangzhou University of Chinese Medicine (Guangzhou, China). All animal experiments were performed in accordance with the policies and principles in the Guide for Care and Use of Laboratory Animals (20). In addition, rabbits were housed as previously described (20). A rabbit femoral bone defect model was generated using a custom-made distraction support, as previously reported (21). Briefly, the rabbit was anesthetized with sodium pentobarbital $(25 \mathrm{mg} / \mathrm{kg})$ and xylazine $(8 \mathrm{mg} / \mathrm{kg})$. A 2-mm Kirschner wire was used to penetrate the double bone cortex $(\sim 20 \mathrm{~mm})$, and was fixed with a tension bracket $200 \mathrm{~mm}$ from the skin. The rectus femoris from the vastus lateralis muscle was then bluntly separated, and the medial rectus muscle was opened, and a $14-\mathrm{mm}$ defect in length was generated in the femur.

Femoral samples were collected from the rabbits, which were randomly divided into three experimental groups of 14 rabbits each: Control group (phosphate-buffered saline, PBS), BMSC group, and BMSC+TGF- $\beta 1$ group. An osteotomy was generated (1.4 cm in length), and the speed and quality of new bone formation was then observed and assessed. The established rabbit femoral defect models were then treated with PBS, BMSCs, or TGF- $\beta 1$-overexpressing BMSCs for 2 or 6 weeks. The study was approved by the Animal Care and Use Committee of Guangzhou University of Chinese Medicine.

Isolation, culture and verification of rabbit BMSCs. The BMSCs were obtained from the rabbit tibiae and femora. Density gradient centrifugation $\left(800 \mathrm{x} \mathrm{g}, 5 \mathrm{~min}, 22^{\circ} \mathrm{C}\right)$ and adherent screening were used to isolate BMSCs, as previous described (10). The tibiae and femora were flushed with Low glucose-Dulbecco's modified Eagle's medium (L-DMEM) (Invitrogen; Thermo Fisher Scientific, Inc., Waltham, MA, USA), and the BMSCs were cultured in L-DMEM supplemented with $10 \%$ fetal bovine serum (Invitrogen; Thermo Fisher Scientific, Inc.) and $1 \%$ penicillin-streptomycin, and incubated with $5 \% \mathrm{CO}_{2}$ at $37^{\circ} \mathrm{C}$. BMSCs from the third passage were used for all experiments in the present study.
Reverse transcription-quantitative polymerase chain reaction (RT-qPCR) analysis. Total RNA was isolated from rabbit BMSCs using TRIzol reagent (cat. no. 15596026, Invitrogen; Thermo Fisher Scientific, Inc., Waltham, MA, USA) according to the manufacturer's protocol. The TGF- $\beta 1$ RT reaction was performed with the TaqMan RNA Reverse Transcription kit (cat. no. 4366596; Applied Biosystems; Thermo Fisher Scientific, Inc.) according to the manufacturer's protocol. cDNA was reverse-transcribed from $2 \mu \mathrm{g}$ total RNA using a Reverse Transcription kit (Takara, Biochemical, Tokyo, Japan). cDNA was then amplified using SYBR GREEN PCR Master mix (cat. no. 638320, Takara Biotechnology Co., Ltd., Dalian, China) according to the manufacturer's protocols and analyzed with an ABI7500 Real-time PCR system (Applied Biosystems; Thermo Fisher Scientific, Inc.). Following the reaction, the $\mathrm{Cq}$ value was obtained, and the results were analyzed using the $2^{-\Delta \Delta C q}$ method (22). The expression of $T G F-\beta 1$ was normalized to the expression of glyceraldehyde 3-phosphate dehydrogenase $(G A P D H)$. All data are presented as the mean \pm standard deviation of three independent experiments. The qPCR cycling conditions were as follows: Pre-denaturing at $95^{\circ} \mathrm{C}$ for $10 \mathrm{~min}$, followed by 40 cycles of denaturing at $95^{\circ} \mathrm{C}$ for $10 \mathrm{sec}$, annealing at $58^{\circ} \mathrm{C}$ for $20 \mathrm{sec}$, and extension at $72^{\circ} \mathrm{C}$ for $10 \mathrm{sec}$. The specific PCR primers used were as follows: GAPDH, forward 5'-ATGTCGTGGAGTCTACTGGC-3; and reverse 5'-TGACCTTGCCCACAGCCTTG-3'; TGF- $\beta 1$, forward 5'-CAGCAACAATTCCTGGCGATA-3' and reverse 5'-AAGGCGAAAGCCCTCAATTT-3'.

Western blot analysis. Proteins were extracted from the rabbit BMSCs with radio-immunoprecipitation assay buffer (cat. no. R0278; Sigma-Aldrich; Merck KGaA, Darmstadt, Germany) containing Protease Inhibitor Cocktail (Thermo Fisher Scientific, Inc.). The total protein concentration was determined using the protein assay kit (Qcbio Science Technologies Co., Ltd., Shanghai, China). Total proteins $(30 \mu \mathrm{g})$ were separated by electrophoresis with $10 \%$ SDS-PAGE and transferred onto a polyvinylidene fluoride (EMD Millipore) membrane. The membrane was blocked with 5\% skim milk and incubated with the respective primary antibodies at $4^{\circ} \mathrm{C}$ overnight. The membrane was washed and incubated with horseradish peroxidase (HRP)-conjugated secondary antibody (1:5,000; cat. no. 115-035-003; Jackson ImmunoResearch Laboratories, Inc., West Grove, PA, USA) the following day at room temperature for $2 \mathrm{~h}$, and the blots were analyzed by enhanced chemiluminescence (ECL) using the ECL substrate kit (Amersham; GE Healthcare Life Sciences, Chalfont, UK). The primary antibodies used were as follows: Anti-TGF- $\beta 1$ (1:1,000; cat. no. ab66043; Abcam, Cambridge, UK) and anti-GAPDH (cat. no. FL-335, an internal loading control, 1:2,000; Santa Cruz Biotechnology, Inc., Santa Cruz, CA, USA).

Enzyme-linked immunosorbent assay (ELISA). The culture supernatant was harvested from rabbit BMSCs transfected with the TGF- $\beta 1$ construct or from non-transfected BMSCs, which served as the negative control (NC). The activity of alkaline phosphatase (ALP) in the culture medium was detected using the ELISA kit (R\&D Systems, Inc., Minneapolis, MN, USA) according to the manufacturer's protocol. A 96-well 

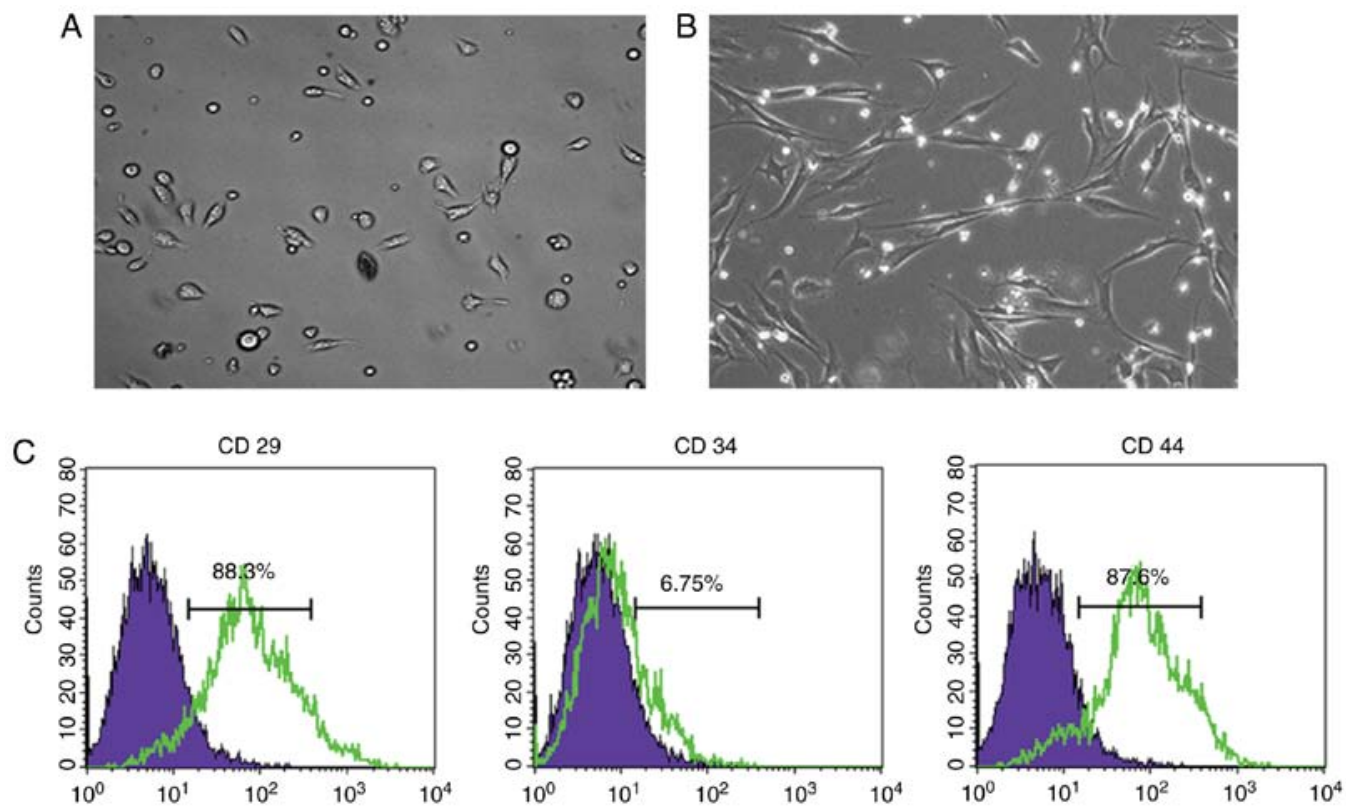

Figure 1. Identification of rabbit BMSCs. Rabbit BMSCs were cultured and amplified in vitro, and images of the morphology of the (A) first passage and (B) third passage of rabbit BMSCs were captured under a light microscope. (C) Surface markers of BMSCs were determined by flow cytometry. Scale bar $=100 \mu \mathrm{m}$. BMSCs, bone marrow-derived mesenchymal stem cells.

plate was coated with a monoclonal anti-ALP antibody (1:1,000 dilution; SAB2500128; Sigma-Aldrich; Merck $\mathrm{KGaA}$ ) for $1 \mathrm{~h}$ at room temperature, which was then detected with a HRP-conjugated secondary antibody (1:30,000 dilution; A0545; Sigma-Aldrich; Merck KGaA) for $1 \mathrm{~h}$ at room temperature. The absorbance at $450 \mathrm{~nm}$ was determined using a microtiter plate reader (Multiskan Go microplate reader, Thermo Fisher Scientific, Inc.).

Masson's staining. Masson's staining was performed to observe the histopathology of the rabbit femoral defects. The treated rabbit femoral defects were washed twice with Dulbecco's-PBS, fixed with cold methanol for $10 \mathrm{~min}$ at $4^{\circ} \mathrm{C}$, washed twice with sterile water, and then stained with the Masson stain kit (Diagnostic BioSystems, Pleasanton, CA, USA). The stained samples were observed and images were captured under a light microscope.

Alizarin red staining. The cells were stained with Alizarin Red $\mathrm{S}$ to detect calcium deposition (23). The BMSCs were washed three times with PBS and then fixed with $70 \%$ ethanol for $1 \mathrm{~h}$ at $4^{\circ} \mathrm{C}$. Following fixation, the cells were washed with water and stained with $0.2 \%$ Alizarin red (Sigma-Aldrich; Merck $\mathrm{KGaA}$ ) in $2 \%$ ethanol for $15 \mathrm{~min}$, and then washed three times with water, and dried at $37^{\circ} \mathrm{C}$.

Transmission electron microscopy (TEM). The samples were prepared and analyzed as previously described (24). Briefly, the samples were fixed and sectioned to $60 \mathrm{~nm}$ using an MTXL RMC ultramicrotome (Boeckeler Instruments Inc., Tucson, AZ, USA), and stained with $1 \%$ toluidine blue. The sections were observed using a Morgagni 268 TEM (FEI Company, Eindhoven, The Netherlands) at $80 \mathrm{kV}$. Images were captured using MegaView III CCD using iTEM-SIS software (Olympus, Soft Imaging System GmbH, Münster, Germany).
$X$-ray microtomography. The rabbit femoral defect model was established and treated with PBS, BMSCs, or TGF- $\beta 1$-overexpressing BMSCs for 2 and 6 weeks. The rabbits were anesthetized with xylazine $(5 \mathrm{mg} / \mathrm{kg})$ and ketamine $(25 \mathrm{mg} / \mathrm{kg})$. An X-ray source was then used to irradiate the right forelimb of the rabbits. X-ray irradiation (MI-201, Shimadzu Corporation, Kyoto, Japan) was used to detect the right ulna, radius, and surrounding soft tissues.

Statistical analysis. All data are presented as the mean \pm standard deviation. The statistical analysis was performed using SPSS 13.0 (SPSS, Inc., Chicago, IL, USA), and statistical significance was assessed using Student's t-test or one-way analysis of variance (ANOVA) test followed by a Student-Newman-Keuls post hoc test. $\mathrm{P}<0.05$ was considered to indicate a statistically significant difference.

\section{Results}

Characterization of rabbit BMSCs. The rabbit BMSCs were cultured, and the first and third passages were observed. As shown in Fig. 1A and B, the cultured BMSCs exhibited a round shape at passage 1 (Fig. 1A) and spindle-shaped morphology at passage 3 (Fig. 1B). Flow cytometry was performed to characterize BMSC surface markers; $88.3 \%$ of the BMSCs were CD29-positive and $87.6 \%$ of the BMSCs were CD44-positive, whereas $<6.75 \%$ of the BMSCs were CD34-positive (Fig. 1C).

TGF- $\beta 1$ is stably overexpressed in rabbit BMSCs and improves osteogenesis. To evaluate whether TGF- $\beta 1$ was overexpressed in the BMSCs, RT-qPCR analysis was performed and the results indicated that the mRNA expression of TGF- $\beta 1$ was high in the BMSCs transfected with TGF- $\beta 1$, compared with 

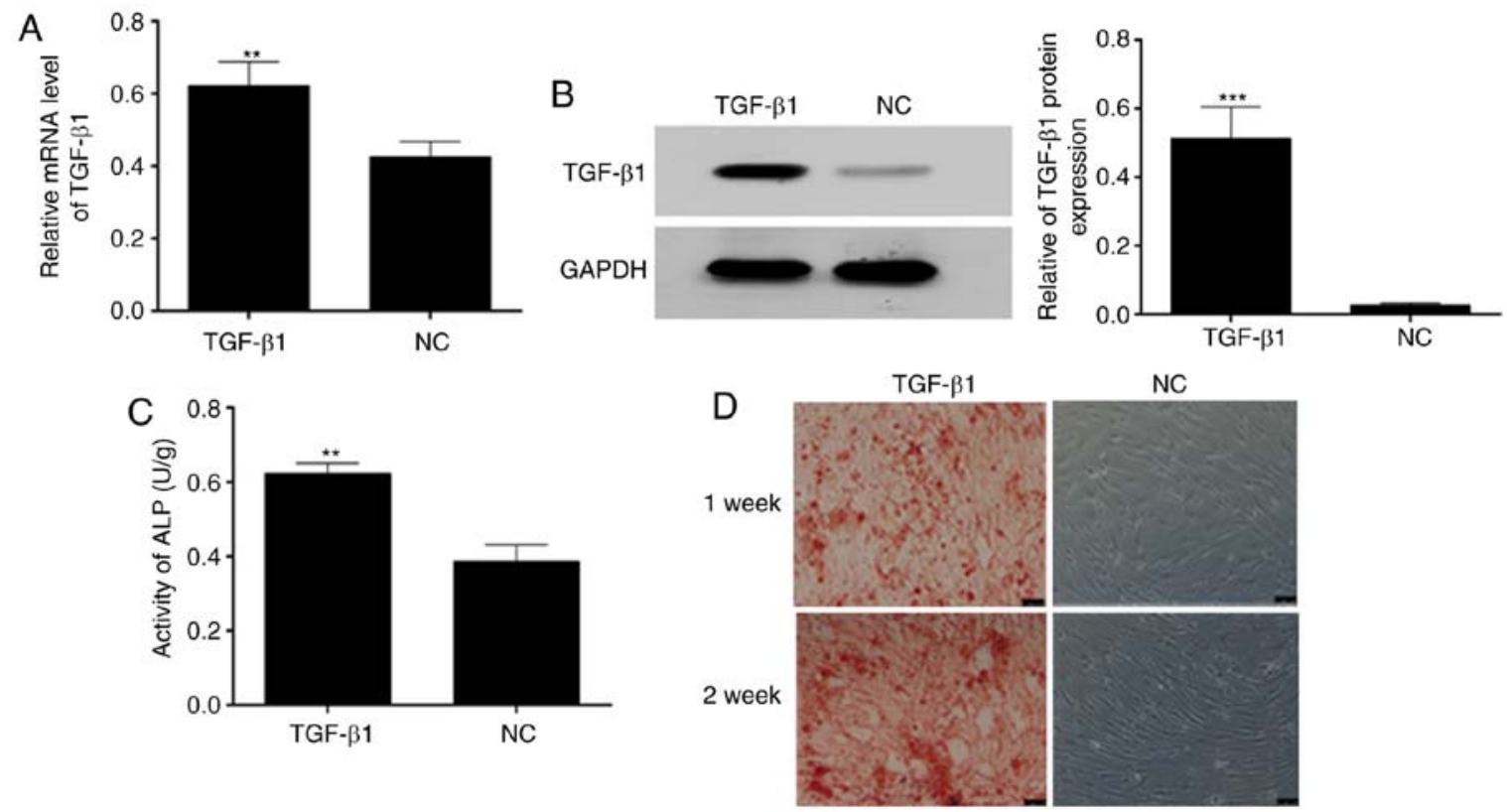

Figure 2. Overexpression of TGF- $\beta 1$ in rabbit BMSCs. (A) mRNA levels of $T G F-\beta 1$ in rabbit BMSCs were quantified using reverse transcription-quantitative polymerase chain reaction. (B) Protein expression of TGF- $\beta 1$ in BMSCs measured using western blot analysis. (C) Activity of ALP in the culture medium of TGF- $\beta 1$-overexpressing BMSCs measured using ELISA. (D) Alizarin red staining of BMSCs at week 1 and week 2 post-culture. ${ }^{* *} \mathrm{P}<0.01,{ }^{* * * *} \mathrm{P}<0.001$ vs. NC. Scale bar=200 $\mu \mathrm{m}$. BMSCs, bone marrow-derived mesenchymal stem cells; TGF- $\beta 1$, transforming growth factor- $\beta 1$; GAPDH, glyceraldehyde 3 -phosphate dehydrogenase; ALP, alkaline phosphatase; NC, negative control.

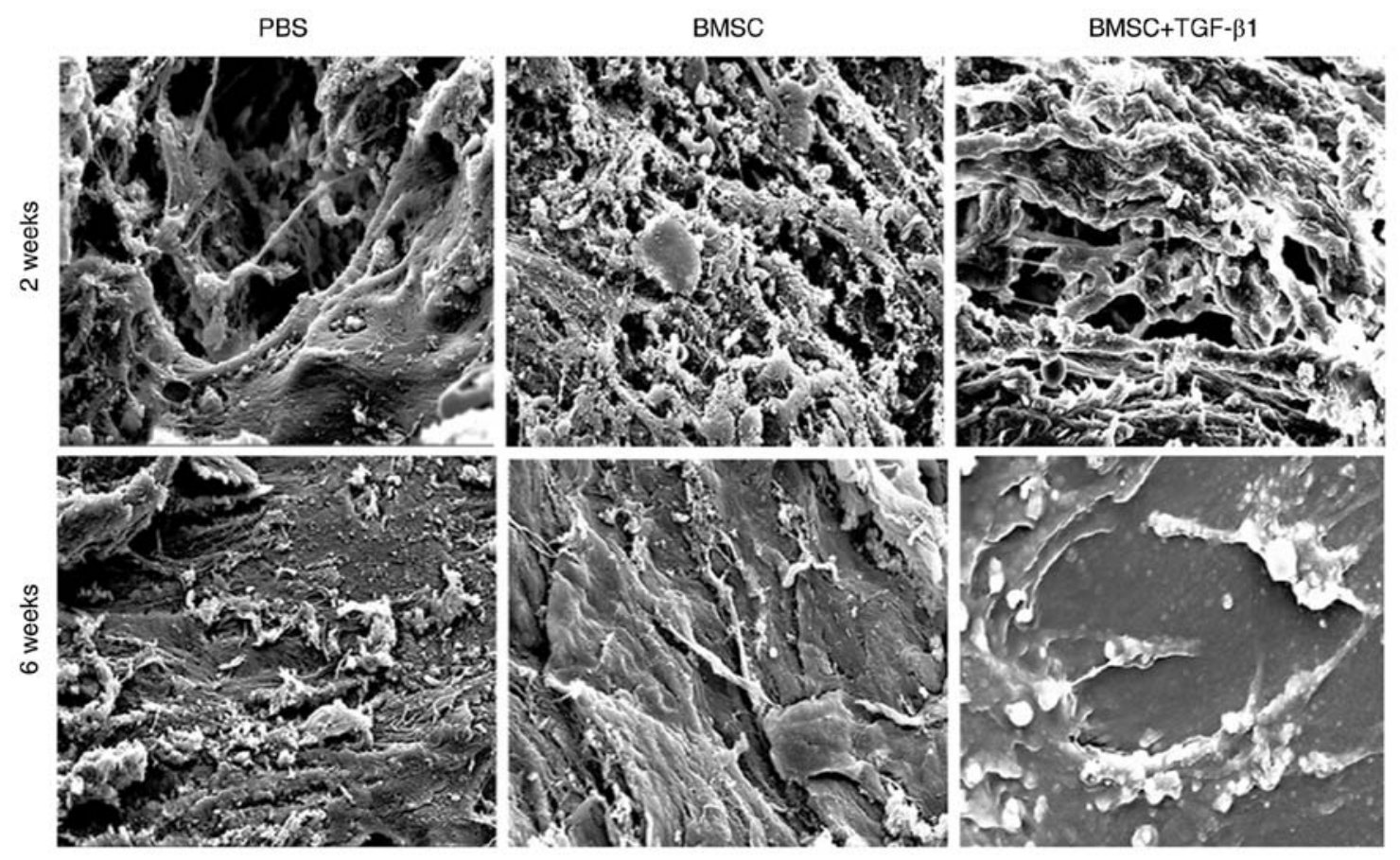

Figure 3. New bone ultrastructure under electron microscope. New bone ultrastructure of the femoral defects treated with PBS, BMSCs, or TGF- $\beta 1$-overexpressing BMSCs (BMSC+TGF- $\beta 1$ ) for 2 and 6 weeks. Scale bar=10 $\mu \mathrm{m}$. BMSCs, bone marrow-derived mesenchymal stem cells; PBS, phosphate-buffered saline; TGF- $\beta 1$, transforming growth factor- $\beta 1$.

that in the NC BMSCs (Fig. 2A). This was consistent with the results of western blot analysis (Fig. 2B). In addition, the ELISA results showed that the activity of ALP was higher in the BMSCs transfected with TGF- $\beta 1$ than in the NC BMSCs (Fig. 2C). Furthermore, TGF- $\beta 1$ improved the osteogenesis of the BMSCs (Fig. 2D).
Expression of TGF- $\beta 1$ is high in newly formed bone of femoral defects treated with TGF- $\beta 1$-overexpressing BMSCs. New bone ultrastructure of the rabbit femoral defect models was determined using electron microscopy. The femoral defects treated with TGF- $\beta 1$-overexpressing BMSCs exhibited improved bone formation (Fig. 3), whereas in the control 

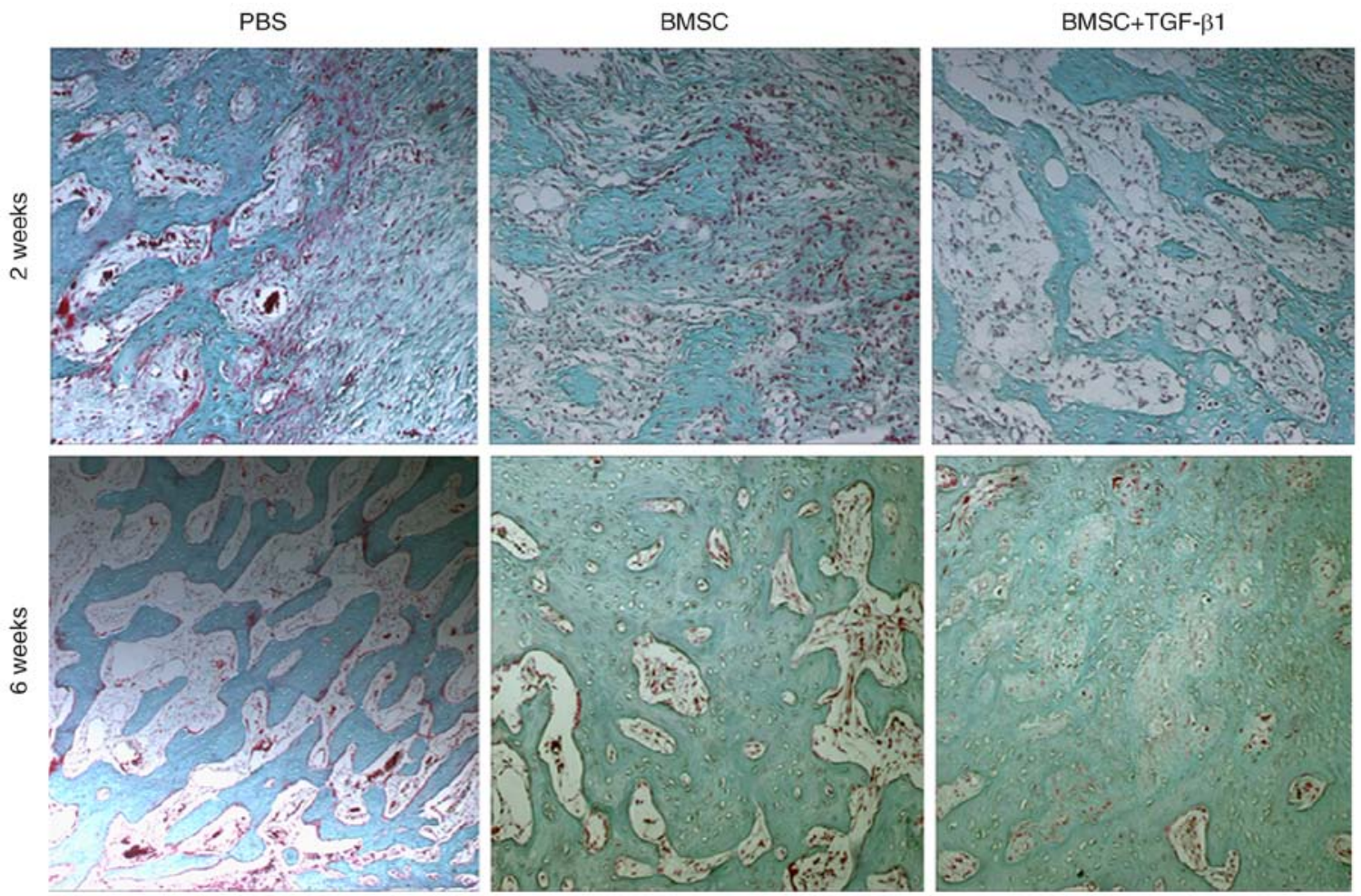

Figure 4. Histopathology of femoral defects treated with TGF- $\beta 1$-overexpressing BMSCs. Trichrome staining of femoral defects treated with PBS, BMSCs, or TGF- $\beta 1$-overexpressing BMSCs for 2 and 6 weeks. Scale bar=50 $\mu \mathrm{m}$. BMSCs, bone marrow-derived mesenchymal stem cells; PBS, phosphate-buffered saline; TGF- $\beta 1$, transforming growth factor- $\beta 1$.

groups, there were numerous collagen fiber bundles arranged in a single direction and fewer new osteoids.

Treatment with TGF- $\beta 1$-overexpressing BMSCs promotes new bone formation in femoral defects. As shown in Table I, it was found that the maximum torque, failure angle, failure energy, and torsional rigidity were significantly increased in the femoral defects treated with the TGF- $\beta 1$-overexpressing BMSCs, compared with those in the PBS- and BMSC-treated control groups. In the BMSC- and TGF- $\beta 1$-overexpressing BMSC-treated groups, the bone surface was smooth, the trabecular bone was relatively dense, and calcification was more complete and closer to that in the normal bone surface (Fig. 4). X-ray analysis further demonstrated that the alignment of the majority of femurs was well-maintained 2 weeks following surgery, and the implants were in a stable position in the TGF- $\beta 1$-overexpressing BMSC group. However, a number of implants in the control group had partially collapsed. In all three groups, a cartilaginous callus had formed and surrounded the majority of the implant, although gaps were visible. At 6 weeks post-surgery, the cartilaginous callus began to take shape and was remodeled into a thin cortical lamellar bone, with the presence of gaps disappearing in all three groups. However, the remodeled cortical lamellar bone was closer to the natural bone in the femoral defects treated with TGF- $\beta 1$-expressing BMSCs than in that in the control group (Fig. 5).

TGF- $\beta 1$-overexpressing BMSC treatment increases bone-related markers in the rabbit femoral defect model. To determine whether TGF- $\beta 1$-overexpressing BMSCs increase bone formation, bone-related markers, including SATB

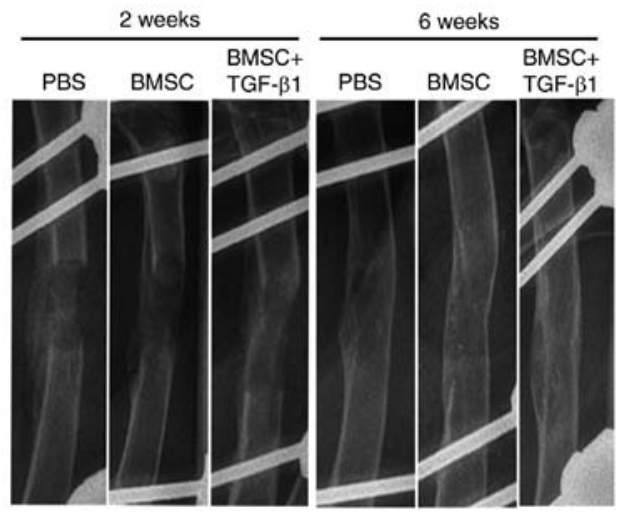

Figure 5. X-ray imaging of external fixator and callus. X-ray imaging of femoral defects treated with PBS, BMSCs, or TGF- $\beta 1$-overexpressing BMSCs at week 2 and week 6 . BMSCs, bone marrow-derived mesenchymal stem cells; PBS, phosphate-buffered saline; TGF- $\beta 1$, transforming growth factor- $\beta 1$

homeobox 2 (Satb2), Runt-related transcription factor 2 (Runx2) and osteocalcin $(\mathrm{OCN})$, were quantified using RT-qPCR and western blot analyses. As shown in Fig. 6A and B, compared with the PBS-treated control group, significant increases were detected in these three markers following treatment with TGF- $\beta 1$-overexpressing BMSCs at weeks 2 and 6.

\section{Discussion}

Distraction osteogenesis is an effective novel method for treating bone defects. However, clinical problems associated with this method, including the long treatment cycle, remain. 
Table I. Biomechanical indices of rabbit femoral defects.

\begin{tabular}{|c|c|c|c|c|}
\hline Group & $\begin{array}{l}\text { Maximum } \\
\text { torque }(\mathrm{Nm})\end{array}$ & $\begin{array}{c}\text { Failure } \\
\text { angle (radian) }\end{array}$ & $\begin{array}{l}\text { Failure energy } \\
\text { (Nm x angle) }\end{array}$ & $\begin{array}{l}\text { Torsional rigidity } \\
\text { (Nm/angle) }\end{array}$ \\
\hline A & $0.205 \pm 0.035$ & $3.136 \pm 0.112$ & $3.215 \pm 0.165$ & $0.021 \pm 0.005$ \\
\hline B & $0.403 \pm 0.059^{\mathrm{a}}$ & $5.232 \pm 0.106^{\mathrm{a}}$ & $4.136 \pm 0.325^{\mathrm{a}}$ & $0.027 \pm 0.003$ \\
\hline $\mathrm{C}$ & $0.457 \pm 0.048^{\mathrm{b}}$ & $5.243 \pm 0.162^{b}$ & $4.225 \pm 0.568^{a}$ & $0.045 \pm 0.006^{\mathrm{b}}$ \\
\hline $\mathrm{D}$ & $0.402 \pm 0.065$ & $5.163 \pm 0.157$ & $4.207 \pm 0.149$ & $0.033 \pm 0.002$ \\
\hline $\mathrm{E}$ & $0.654 \pm 0.074^{c}$ & $5.373 \pm 0.168$ & $6.355 \pm 0.186^{\mathrm{d}}$ & $0.052 \pm 0.004^{\mathrm{c}}$ \\
\hline $\mathrm{F}$ & $0.698 \pm 0.046^{\mathrm{d}}$ & $7.454 \pm 0.194^{\mathrm{d}}$ & $7.526 \pm 0.512^{\mathrm{e}}$ & $0.068 \pm 0.005^{\mathrm{d}}$ \\
\hline
\end{tabular}

Rabbit femoral defect models were established and treated for 2 weeks with (A) PBS, (B) BMSCs or (C) transforming growth factor- $\beta 1$-expressing BMSCs, and for 6 weeks with (D) PBS, (E) BMSCs or (F) transforming growth factor- $\beta 1$-expressing BMSCs. ${ }^{a} \mathrm{P}<0.05$ and ${ }^{\text {b }} \mathrm{P} 0.01$, vs. group A; ${ }^{\mathrm{c}} \mathrm{P}<0.05,{ }^{\mathrm{d}} \mathrm{P}<0.01$ and ${ }^{\mathrm{e}} \mathrm{P}<0.00$, vs. group D. BMSCs, bone marrow-derived mesenchymal stem cells; PBS, phosphate-buffered saline.
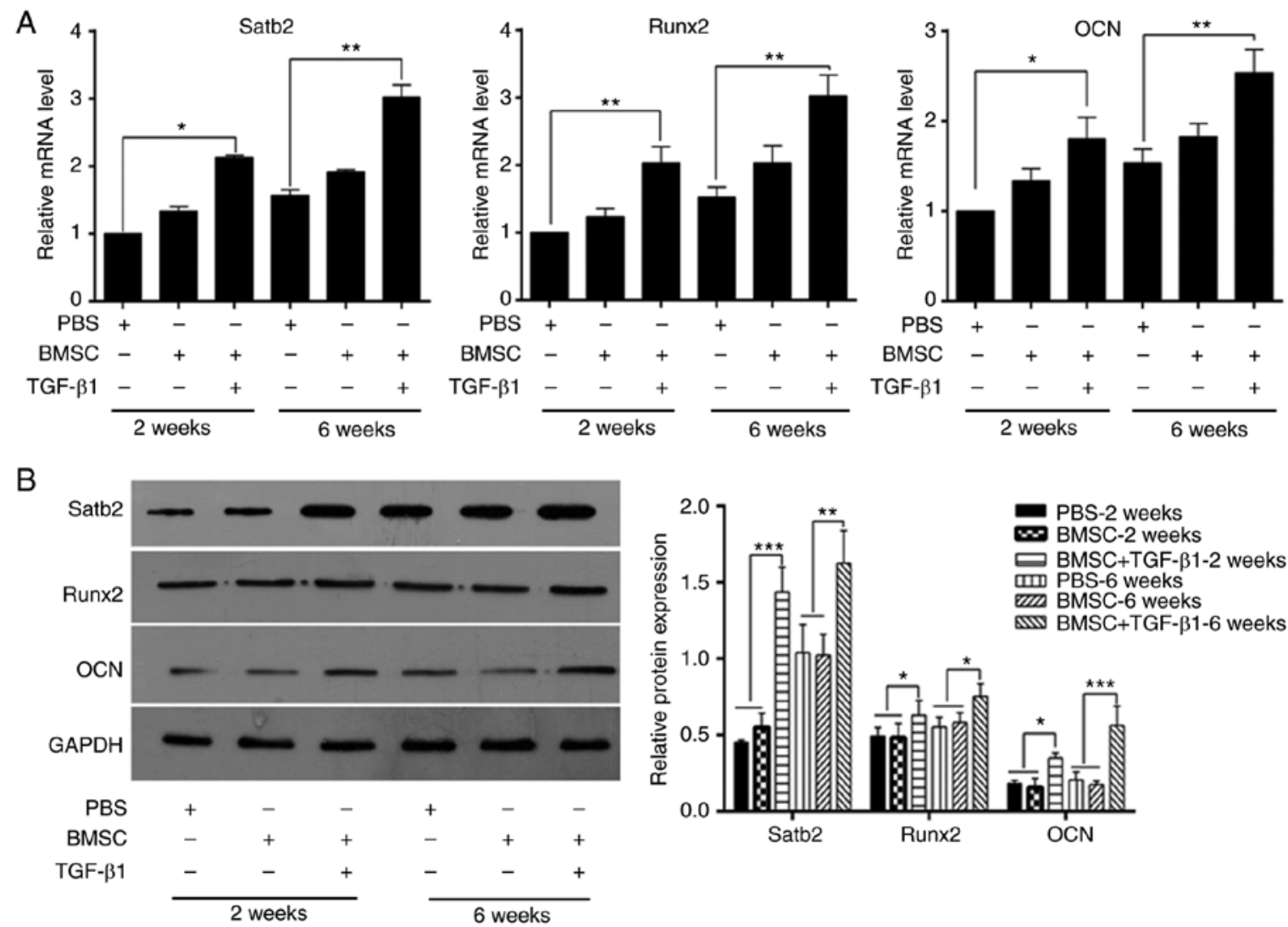

Figure 6. Expression of bone-related markers in TGF- $\beta 1$-overexpressing BMSCs treated femoral defects. (A) mRNA levels of Satb2, Runx2, and OCN in femoral defects treated with PBS, BMSCs, or TGF- $\beta 1$-overexpressing BMSCs at week 2 and week 6 , quantified by reverse transcription-quantitative polymerase chain reaction analysis $\left({ }^{*} \mathrm{P}<0.05\right.$; $\left.{ }^{* * *} \mathrm{P}<0.01\right)$. (B) Protein expression of Satb2, Runx2, and OCN in femoral defects treated with PBS, BMSCs, or TGF- $\beta 1$-overexpressing BMSCs at week 2 and week 6 , measured by western blot analysis $\left({ }^{*} \mathrm{P}<0.05 ;{ }^{* *} \mathrm{P}<0.01 ;{ }^{* * *} \mathrm{P}<0.001\right)$. BMSCs, bone marrow-derived mesenchymal stem cells; PBS, phosphate-buffered saline; TGF- $\beta 1$, transforming growth factor- $\beta 1$; Satb2, SATB homeobox 2 ; Runx 2 , Runt-related transcription factor 2; OCN, osteocalcin; GAPDH, glyceraldehyde 3-phosphate dehydrogenase.

Therefore, a large number of studies have been performed to accelerate the ossification and shorten the treatment process using various methods. Studies have shown that combining growth factors with distraction osteogenesis can effectively shorten the duration of treatment $(25,26)$. However, the delivery of growth factors into the defective region remains challenging. In addition, the cost of growth factor treatment is prohibitive for the majority of patients. Therefore, the development of novel strategies that are effective and convenient is critical.

Mesenchymal stem cells (MSCs) are the progenitor cells of connective tissues, including adipose tissue, cartilage and bone (27). BMSCs are a type of pluripotent MSC. Under specific induction conditions, BMSCs can differentiate into various cell types, including bone cells. Therefore, BMSCs offer potential for treating musculoskeletal injuries and 
disorders. In addition, BMSCs can be readily separated and cultured, with high proliferation capacity and weak immunogenicity, making them ideal for tissue engineering (28).

TGF- $\beta 1$ is one of the most important cytokines in the bone matrix (29). Previous studies have shown that it is involved in a variety of biological processes, including development, apoptosis, proliferation, inflammation, bone formation, differentiation and tumor growth. TGF- $\beta 1$ can be activated by dissociation from latency-associated peptide, when tissue is injured or remolded $(30,31)$. TGF- $\beta$ then rapidly recruits perivascular MSCs to the bone surface for osteoblast differentiation and new bone formation (32). Therefore, TGF- $\beta$ has significant effects on bone homeostasis during remodeling by recruiting MSCs.

In the present study, TGF- $\beta 1$ was stably overexpressed in rabbit BMSCs to evaluate the effects of TGF- $\beta 1$ in combination with BMSCs on new bone formation in a rabbit femoral defect model. The results showed that TGF- $\beta 1$ was expressed at a high level in the new bone of the femoral defects treated with TGF- $\beta 1$-overexpressing BMSCs, and that the combination of BMSCs and TGF- $\beta 1$ significantly promoted the formation of new bone. In the femoral defects treated with TGF- $\beta 1$-overexpressing BMSCs, the bone surface was smooth, the trabecular bone was relatively dense, and the calcification was more complete and closer to that of the normal bone surface. In addition, in this TGF- $\beta 1$-overexpressing BMSC group, the remodeled cortical lamellar bone was closer to natural bone than that of the control group, and the cartilaginous callus began to take shape and was remodeled into thin cortical lamellar bone. Therefore, the results suggested that TGF- $\beta 1$, in combination with BMSCs, promoted new bone formation in the rabbit femoral defect model. Previous studies have shown that TGF- $\beta$ is important in the repair of BMSC-mediated subchondral osteoarthritis (33), as the bone matrix releases and activates TGF- $\beta$, and the active TGF- $\beta$ recruits MSCs to the bone resorption pit (34). Therefore, TGF- $\beta$ signaling is crucial in the formation of new bone by BMSCs.

\section{Acknowledgements}

Not applicable.

\section{Funding}

This study was supported by Shandong Provincial Natural Science Foundation (grant no. BS2014YY026) and the Foshan Municipal Health Bureau for Scientific Research (grant nos. 20170161 and 20180184).

\section{Availability of data and materials}

All data generated or analysed during this study are included in this published article.

\section{Authors' contributions}

BYS, BXZ, JYZ, ZPS, YAS and FH made substantial contributions to the conception and design of the present the study. BYS, BXZ, JYZ and ZPS performed the experiments. BYS and $\mathrm{BXZ}$ wrote the paper. YAS and $\mathrm{FH}$ revised the manuscript critically for important intellectual content. All authors read and approved the manuscript.

\section{Ethics approval and consent to participate}

The present study was approved by the Animal Care and Use Committee of Guangzhou University of Chinese Medicine and experiments were performed in accordance with the policies and principles in the Guide for Care and Use of Laboratory Animals (20).

\section{Consent for publication}

Not applicable.

\section{Competing interests}

The authors declare that they have no competing interests.

\section{References}

1. Yelin E, Weinstein S and King T: The burden of musculoskeletal diseases in the United States. Semin Arthritis Rheum 46: 259-260, 2016.

2. Qu D, Mosher CZ, Boushell MK and Lu HH: Engineering complex orthopaedic tissues via strategic biomimicry. Ann Biomed Eng 43: 697-717, 2015.

3. Goodrich JT, Sandler AL and Tepper O: A review of reconstructive materials for use in craniofacial surgery bone fixation materials, bone substitutes, and distractors. Childs Nerv Syst 28: 1577-1588, 2012.

4. Mendes SC, Tibbe JM, Veenhof M, Bakker K, Both S, Platenburg PP, Oner FC, de Bruijn JD and van Blitterswijk CA: Bone tissue-engineered implants using human bone marrow stromal cells: Effect of culture conditions and donor age. Tissue Eng 8: 911-920, 2002.

5. Suzuki Y, Kim KJ, Kotake S and Itoh T: Stromal cell activity in bone marrow from the tibia and iliac crest of patients with rheumatoid arthritis. J Bone Miner Metab 19: 56-60, 2001.

6. Rodriguez JP, Montecinos L, Rios S, Reyes P and Martinez J: Mesenchymal stem cells from osteoporotic patients produce a type I collagen-deficient extracellular matrix favoring adipogenic differentiation. J Cell Biochem 79: 557-565, 2000.

7. Johnson PC, Mikos AG, Fisher JP and Jansen JA: Strategic directions in tissue engineering. Tissue Eng 13: 2827-2837, 2007.

8. Kim K, Dean D, Lu A, Mikos AG and Fisher JP: Early osteogenic signal expression of rat bone marrow stromal cells is influenced by both hydroxyapatite nanoparticle content and initial cell seeding density in biodegradable nanocomposite scaffolds. Acta Biomater 7: 1249-1264, 2011

9. Friedenstein AJ, Chailakhjan RK and Lalykina KS: The development of fibroblast colonies in monolayer cultures of guinea-pig bone marrow and spleen cells. Cell Tissue Kinet 3: 393-403, 1970.

10. Pittenger MF, Mackay AM, Beck SC, Jaiswal RK, Douglas R, Mosca JD, Moorman MA, Simonetti DW, Craig S and Marshak DR: Multilineage potential of adult human mesenchymal stem cells. Science 284: 143-147, 1999.

11. Hosseinkhani M, Mehrabani D, Karimfar MH, Bakhtiyari S, Manafi A and Shirazi R: Tissue engineered scaffolds in regenerative medicine. World J Plast Surg 3: 3-7, 2014.

12. Kagami H, Agata H, Inoue M, Asahina I, Tojo A, Yamashita N and Imai $\mathrm{K}$ : The use of bone marrow stromal cells (bone marrow-derived multipotent mesenchymal stromal cells) for alveolar bone tissue engineering: Basic science to clinical translation. Tissue Eng Part B Rev 20: 229-232, 2014.

13. Stroncek DF, Sabatino M, Ren J, England L, Kuznetsov SA, Klein HG and Robey PG: Establishing a bone marrow stromal cell transplant program at the National Institutes of Health Clinical Center. Tissue Eng Part B Rev 20: 200-205, 2014. 
14. Polymeri A, Giannobile WV and Kaigler D: Bone marrow stromal stem cells in tissue engineering and regenerative medicine. Horm Metab Res 48: 700-713, 2016.

15. Frangogiannis NG: Inflammation in cardiac injury, repair and regeneration. Curr Opin Cardiol 30: 240-245, 2015.

16. Frangogiannis NG: The inflammatory response in myocardial injury, repair, and remodelling. Nat Rev Cardiol 11: 255-265, 2014.

17. Katsuno Y, Lamouille S and Derynck R: TGF- $\beta$ signaling and epithelial-mesenchymal transition in cancer progression. Curr Opin Oncol 25: 76-84, 2013.

18. Cortez VS, Cervantes-Barragan L, Robinette ML, Bando JK, Wang Y, Geiger TL, Gilfillan S, Fuchs A, Vivier E, Sun JC, et al: Transforming Growth Factor- $\beta$ signaling guides the differentiation of innate lymphoid cells in salivary glands. Immunity 44 $1127-1139,2016$.

19. Andrades JA, Han B, Becerra J, Sorgente N, Hall FL and Nimni ME: A recombinant human TGF-betal fusion protein with collagen-binding domain promotes migration, growth, and differentiation of bone marrow mesenchymal cells. Exp Cell Res 250: 485-498, 1999.

20. Council SN, Washington, Bethesda and MD: Guide for the care and use of Laboratory Animals. Revised edition, 73, 1978.

21. Kim J, McBride S, Dean DD, Sylvia VL, Doll BA and Hollinger JO: In vivo performance of combinations of autograft demineralized bone matrix, and tricalcium phosphate in a rabbit femoral defect model. Biomed Mater 9: 035010, 2014.

22. Livak KJ and Schmittgen TD: Analysis of relative gene expression data using real-time quantitative PCR and the 2(-Delta Delta C(T)) method. Methods 25: 402-408, 2001.

23. Zhao Y, Chen J, Dai X, Cai H, Ji X, Sheng Y, Liu H, Yang L, Chen Y, Xi D, et al: Human glioma stem-like cells induce malignant transformation of bone marrow mesenchymal stem cells by activating TERT expression. Oncotarget 8: 104418-104429, 2017.

24. Kristensen HB, Andersen TL, Marcussen N, Rolighed L and Delaisse JM: Increased presence of capillaries next to remodeling sites in adult human cancellous bone. J Bone Miner Res 28: 574-585, 2013.

25. Makhdom AM and Hamdy RC: The role of growth factors on acceleration of bone regeneration during distraction osteogenesis. Tissue Eng Part B Rev 19: 442-453, 2013.
26. Siwicka KA, Kitoh H, Kawasumi M and Ishiguro N: Spatial and temporal distribution of growth factors receptors in the callus: Implications for improvement of distraction osteogenesis. Nagoya J Med Sci 73: 117-127, 2011.

27. Caplan AI: New MSC: MSCs as pericytes are Sentinels and gatekeepers. J Orthop Res 35: 1151-1159, 2017.

28. van Gorp S, Leerink M, Kakinohana O, Platoshyn O, Santucci C, Galik J, Joosten EA, Hruska-Plochan M, Goldberg D, Marsala S, et al: Amelioration of motor/sensory dysfunction and spasticity in a rat model of acute lumbar spinal cord injury by human neural stem cell transplantation. Stem Cell Res Ther 4: 57, 2013.

29. Hering S, Isken E, Knabbe C, Janott J, Jost C, Pommer A Muhr G, Schatz H and Pfeiffer AF: TGFbeta1 and TGFbeta2 mRNA and protein expression in human bone samples. Exp Clin Endocrinol Diabetes 109: 217-226, 2001.

30. Dallas SL, Rosser JL, Mundy GR and Bonewald LF: Proteolysis of latent transforming growth factor-beta (TGF-beta)-binding protein-1 by osteoclasts. A cellular mechanism for release of TGF-beta from bone matrix. J Biol Chem 277: 21352-21360, 2002.

31. Brauer PR and Yee JA: Cranial neural crest cells synthesize and secrete a latent form of transforming growth factor beta that can be activated by neural crest cell proteolysis. Dev Biol 155: 281-285, 1993.

32. Pfeilschifter J, Wolf O, Naumann A, Minne HW, Mundy GR and Ziegler R: Chemotactic response of osteoblastlike cells to transforming growth factor beta. J Bone Miner Res 5: 825-830, 1990.

33. Zhen G, Wen C, Jia X, Li Y, Crane JL, Mears SC, Askin FB, Frassica FJ, Chang W, Yao J, et al: Inhibition of TGF- $\beta$ signaling in mesenchymal stem cells of subchondral bone attenuates osteoarthritis. Nat Med 19: 704-712, 2013.

34. Crane JL, Xian L and Cao X: Role of TGF- $\beta$ signaling in coupling bone remodeling. Methods Mol Biol 1344: 287-300, 2016.

(i) $\Theta$ This work is licensed under a Creative Commons Attribution-NonCommercial-NoDerivatives 4.0 International (CC BY-NC-ND 4.0) License. 